\title{
Towards a semio-cognitive theory of Human-Computer Interaction
}

\author{
Carlos A. Scolari \\ Università Cattolica Sacro Cuore di Milano (Italy) \\ Tel. 00390117712645 \\ cscolari@ars-media.it
}

\begin{abstract}
The research here presented is theoretical and introduces a critical analysis of instrumental approaches in HumanComputer Interaction (HCI). From a semiotic point of view interfaces are not "natural" or "neutral" instruments, but rather complex sense production devices. Interaction, in other words, is far from being a "transparent" process.

In this abstract we present the fundaments of a theoretical model that combines Semiotics with Cognitive Science approaches.
\end{abstract}

Keywords
Interfaces, Human-Computer Interaction, semiotics,
transparency

\section{INTRODUCTION}

Along with the diffusion of user-friendly interfaces a new conception of $\mathrm{HCI}$ became popular amongst designers and researchers: the interface is an "instrument" or "tool" that must "disappear" during interaction. User-centered design evangelists have expanded this perception to the last consequence: the best interface is the "invisible" one, i.e. the interaction device that users "don't feel" and allows them to concentrate on accomplishing their task [5].

This principle is valid for any interface: interaction devices of videogames, word-processors or web sites must disappear when the user interacts. Only in cases of system breakdown the user will "feel" the interface [7].

An invisible interface is the utopia for any interface designer. But what's good for a designer -and specially for the user- is not necessarily good for a researcher. The apparent naturalization of interactive processes should not imply -as often occurs in instrumentalist approaches- a loss of theoretical complexity: even the most simple example of HCI (like clicking an icon or activating a "roll-over" device) involves an intricate combination of perceptive and interpretative operations.

Users, not researchers, need an non-visible technology. Then, to design "invisible" interfaces first we must understand the interaction process and bring out its internal sense production machine.

(C) Copyright on this material is held by the Author(s).

\section{CRITIQUE OF INSTRUMENTAL REASON}

Human-computer interfaces, are not neutral or impartial territories like any other place where semiotic and cognitive processes manifest. The purpose of our research is to dismount the myth of interface transparency, identifying the complex semiotic and cognitive processes behind HCI.

\section{Semiotics and cognition}

Why a "semio-cognitive" approach and not just a "cognitive" theory? Because interaction is such a complex and uncertain process that one theory is not enough. HCI is a multidisciplinary field where different approaches can (and should) be applied.

Semiotic is not just the "science of signs" but a theory about "sense production and interpretation". It does not involve real people but operates with virtual models and sense production/interpretation strategies. If we consider HCI a semiotic process, the research must focus on the ambiguous game of sense production and interpretation that involves designers and users.

The main purpose of semiotic research applied to $\mathrm{HCI}$ is not to provide guidelines for interface designers but to create theoretical models of interactive processes. Certainly, semiotic research could provide designers with many models and tips that would optimize the hard art of designing user interfaces.

Umberto Eco's "semiotic of text interpretation" applied many concepts and categories from cognitive field. Concepts like "frame" (M. Minsky) and "script" (R. Shank) have been very important elements of Eco's theory in the 80's [3]. In latter works Eco concludes that semiosis, even on a very simple level (he called it "proto-semiosis"), is also present in every perception process [4]. Our research actualizes this dialogue between Semiotic and Cognitive Science, creating a framework for the construction of a Semio-cognitive Theory of HCI. To break the instrumental reason, our research proposes a theoretical model which is no longer founded on an instrumental conception but on a contractual conception of $\mathrm{HCI}$.

\section{A CONTRACT OF INTERACTION}

How does the HCI process take act from a semiotic approach? Like any written or audiovisual text, an interface -no matter if it is a software, a multimedia encyclopedia, a videogame or a web site- contains a simulacrum of an exchange between two virtual characters: the Implied Designer and the Implied User [1][2]. 
By way of this dialogue between these two virtual characters, designers -like any movie director or novel author- just suggest a proposal of interaction that can be accepted (or refused) by the empirical user [6]. If user accepts this proposal a contract of interaction will be signed between them and the exchange will start. This means that users have decided to share a common semiotic field with the designer of the system.

What happens if users don't accept the interaction contract? They will probably search for another proposal. In this sense we can say that the World Wide Web and the software market is formed by millions of sites and hundreds of software products waiting for users to establish interaction contracts. If this proposal is not clear enough, if the interaction contract is not "attractive", then users will just click away or choose another product. Very often users may decide to utilize the interface in a different way or for other purposes not present in the proposal of interaction.

The study of contracts of interaction must be considered a central issue for usability research and interaction design. Our research renders precise the concept of contract of interaction -not only in digital environments but also in real world context- and illustrates different kinds of interaction proposals.

\section{The user/producer Interactive dynamics}

The traditional cognitive model of $\mathrm{HCI}$ [5] is not sufficient enough to explain the entire process of interaction. If we applied a semiotic approach to interaction, new characters will refine and enrich the traditional cognitive model.

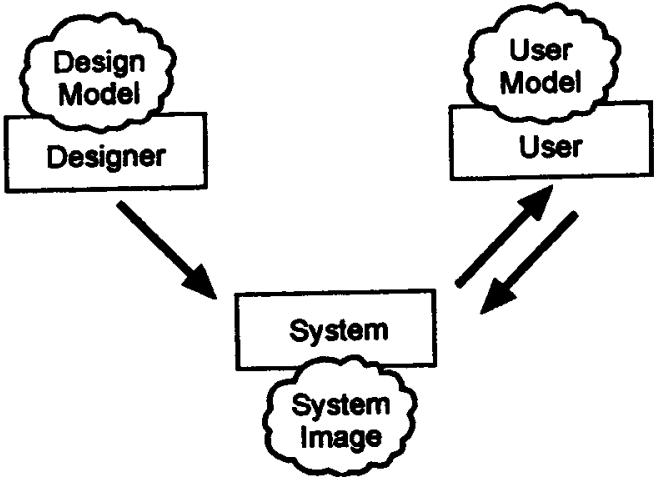

The traditional cognitive model of $\mathrm{HCI}$ [6]

As we have seen, from a semio-cognitive perspective it is possible to identify at least four virtual characters: two inside designer's and user's mind (Design Model and User Model) and another two inside interface (Implied Designer and Implied User). The first two characters have been exhaustively described by Cognitive Science; the second ones are exclusively of Semiotic pertinence.

- Design model: is the mental representation of the system and its potential user inside a designer's mind. Instrumental approaches very often confuse this image with the Implied Designer that is inscribed inside the interface. But as every designer already knows, a digital system never works as expected.

- User model: is the image of the system inside user's mind. This mental representation rarely includes an image of the designer. This is a consequence of the myth of interface transparency: if interfaces are "transparent" and interaction is a "natural" process, then there's no place in this mental model for a human agent.

- Implicit Designer: is a simulacrum of the designer inside the interface. Empirical designers "delegate" their functions in this virtual character. The Implied Designer appears on the interface in form of "traces" and "marks" of an ordering action; these "marks" also determine the time of interaction, i.e. the sequence of inputs and answers [1][2].

- Implicit User: is a simulacrum of the user inside the interface. The Implied User is a hypothesis of user behavior, a presumption about user experience, competence and expectations. If user recognize herself in this virtual character, the proposal of interaction will be accepted and the interaction will start.

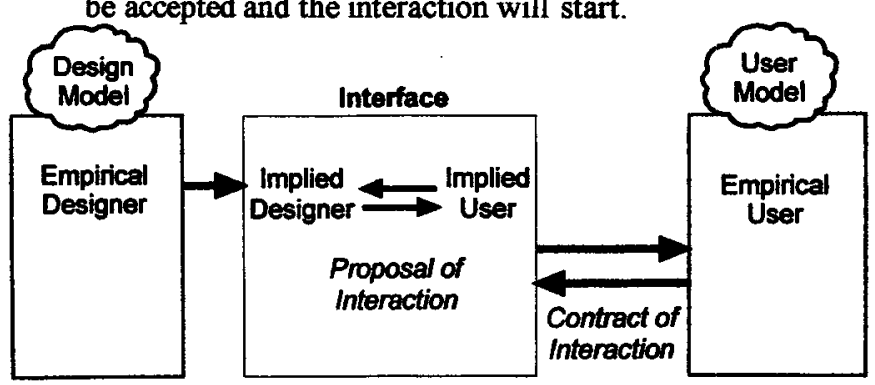

The semio-cognitive model of $\mathrm{HCI}$

As we can see, the Implied Designer and the Implied User are "imprisoned" inside the interface and only semiotic approach can restore their presence. Both virtual characters and specially the "dialogue" between them- leads us to uncover and understand the interaction strategy of the designer and the way in which the interaction process works.

Interfaces are not "tools" that "disappear" during interaction, but rather complex semiotic devices that constraint users to cooperate with designers and to contract with them for the sense of interaction process.

REFERENCES

1. Bettetini, G. La Conversazione Audiovisiva. Bompiani, Milan, 1984.

2. Bettetini, G. La Simulazione Visiva. Bompiani, Milan, 1991.

3. Eco, U. The Role of the Reader. Indiana University Press, 1979.

4. Eco, U. Kant and the Playtpus. Indiana University Press, 1999.

5. Norman, D. The Psychology of Everyday Things. Basic Books, New York, 1988

6. Verón E. L'analyse du 'contrat de lecture': une nouvelle methode pour les estudes de posionnement des supports presse. Les medias: experiences, recherches actuelles, aplications. IREP, Paris, 1985

7. Winograd, T. and Flores, F. Understanding Computers and Cognition. Ablex, Norwood, New Jersey, 1986. 